\title{
The Photon and Endless Energy
}

\author{
Bhekuzulu Khumalo \\ Private Researcher, Toronto, Canada \\ Email: bhekuzulu.khumalo@gmail.com
}

How to cite this paper: Khumalo, B. (2017) The Photon and Endless Energy. Optics and Photonics Journal, 7, 133-138. https://doi.org/10.4236/opj.2017.78013

Received: July 30, 2017

Accepted: August 14, 2017

Published: August 17, 2017

Copyright $\odot 2017$ by author and Scientific Research Publishing Inc. This work is licensed under the Creative Commons Attribution International License (CC BY 4.0).

http://creativecommons.org/licenses/by/4.0/

\begin{abstract}
Light can create itself. Experiments have been carried out and seemingly prove this hypothesis, though the experimenters themselves did not see this phenomenon in front of them. This discussion gives the proof and the implications.
\end{abstract}

\section{Keywords}

Information, Photon Battery, Single Photon, Ziyenza

\section{Aims}

The aim of this paper is to assert the hypothesis that light can self create.

\section{Introduction}

In December 2011, Popular Science magazine reported Video: A Trillion-FramePer Second Camera Captures Individual Photons Moving Through Space [1]. Andreas Velten and Ramesh Raskarthen of MIT Media Lab, created a piece of technology that could record photons as they moved around a coke bottle. The video [2], it has to be watched or one will not appreciate this paper, here is the link https://www.youtube.com/watch?v=_QAPQO6EL8o.

Right there in front of us is the puzzle, how does the camera capture these photons such that we can see the phenomenon when it is slowed down. In normal circumstance photons do not interact with photons, let us not argue about this phenomenon, colliders are not normal circumstances. The photons are in a bottle and we can see them, how is that possible unless the photons are emitting themselves, there is no other explanation possible in this universe. The experiment is proven by the fact the camera took a picture of the photon burst inside the bottle.

The process of light creating itself needs to be understood in the simplest 
manner as possible so that as many people as possible can understand it. The paper starts by looking at light in the container and how this light travels to the camera allowing the camera to take a photo. This is a unique phenomenon and must be given a name. Light is energy and the camera captures energy, this energy can be exploited for commercial purposes in time.

To fully comprehend how much energy a pulse of light contains, a second hypothetical camera is added to the experiment carried out by the MIT Media Lab, that camera too should take photos but from a different locality and this is illustrated and discussed.

The overriding objective of this paper is to show that light creates itself, but once this is proven we must attempt to explain what is happening, how much light the camera takes, and the possibilities are mentioned.

\section{What Is Happening}

Figure 1 illustrates a photon burst inside a container, that container in the demonstration by Velten and Rasker was a coke bottle. It can be any container of similar properties allowing light to behave as it does in the video.

There is a light sensor, a light sensor is anything that can detect light, by what ever method, in this case it happens to be a camera. This is illustrated in Figure 2.

For the camera to be able to take the photo's it needs light. Photons are not eggs, to see an egg light/ photons are reflected and emitted from the egg and the camera can take a photo. Photons do not interact with other photons, photons are not going to be reflected from other photons, the only possible answer is that

\section{Captured Photons in Container}

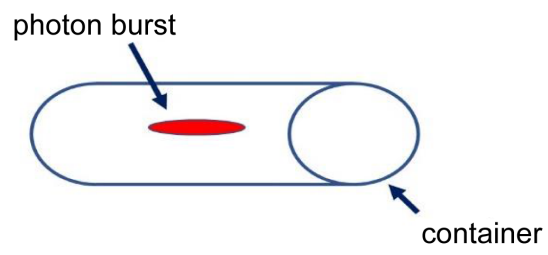

Figure 1. Captured photons in container.

Captured Photons Experiment
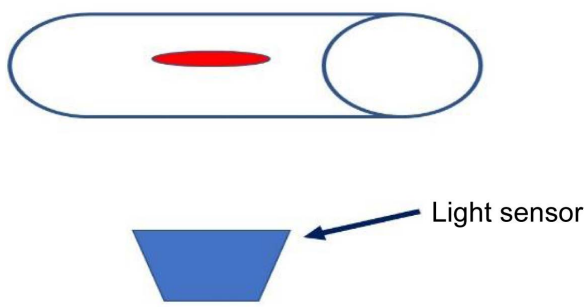

Figure 2. Captured photons experiment. 
the photon is self creating, they are emitting themselves as illustrated in Figure 3.

Figure 3 shows that even though the photons are in the container, a camera outside the container can take pictures, no reflection can be taking place, light is emitting itself, by the mere fact that pictures where taken is beyond proof. We can add another light sensor, another camera if some prefer can be added as in Figure 4.

Hypothetically adding another camera to the MIT Lab will allow us to appreciate how much energy a pulse of light contains, understand the characteristics of pure light and appreciate how much can be extracted from a single pulse of light. The other sensor must sense the light. This means a single photon can create itself in more than one direction, a property that needs to be appreciated over and above the main scope of the discussion that light can create itself. Not only can it create itself, but multiple sensors can, and will sense it placed in the right location.

Adding another camera no doubt will have photos taken from another angle because it is physically impossible for the sensors to occupy the same space no matter how that space is defined, they can not ever overlap. Photo's being taken means not only can the first camera sense the light, but both sensors sense the

Captured Photons Experiment what's going on

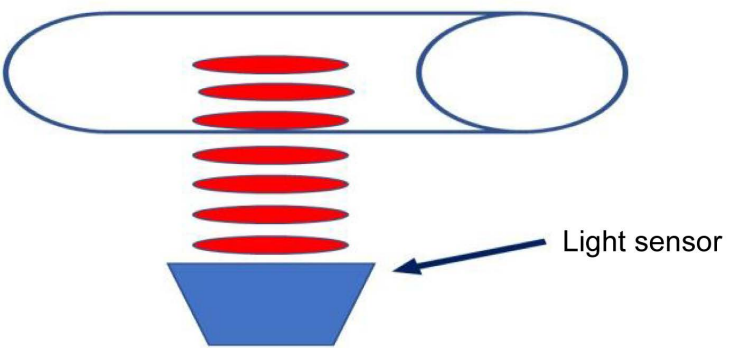

Figure 3. Captured Photons Experiment: what is going on?

Captured Photons Experiment what's going on part 2

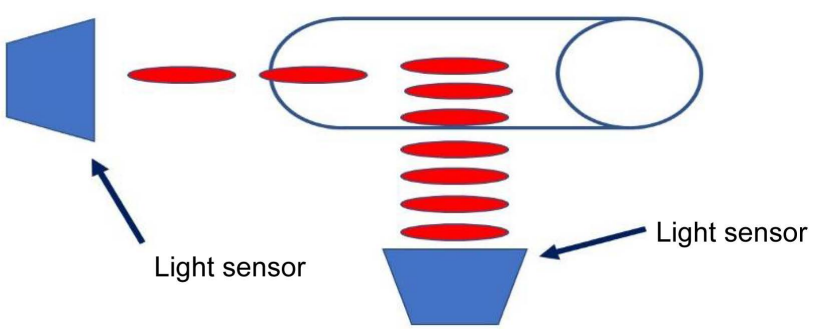

Figure 4. Captured Photons Experiment: what is going on part 2. 
light. This means that light is reproducing itself twice, the reality being that it will seemingly reproduce itself as many times as there are sensors.

The mere fact that a photo is taken, photons absorbed by the sensor, this is proof enough of what is taking place, other wise the photons that created the photo can not exist but they do exist we see their pattern in the photo. This process we shall call ziyenza, to make oneself.

\section{How Much Energy}

The process of ziyenza, $Z_{a}$, is a rate per time period, it is how much photons are created per time period. This time period should be the smallest time period possible, obviously the concept of ziyenza is new but real, the camera took a photo of light Ziyenza, $Z_{a}$ can be said to have this relationship with time,

$$
Z_{a}=\#_{P} \text { pert }_{p}
$$

where $\#_{\mathrm{p}}$ is number of photons and $t_{p}$ is the Planck time. Let us say we have a burst of light, or a captured group of photons as illustrated in Figure 5, a pulse of light consisting of 28 photons. The number 28 is arbitrary merely to illustrate a concept.

Let us now place a camera to take photos, what is happening is illustrated in Figure 6.

In Figure 6 we have our pulse of light, $\odot$, consisting of 28 photons. There is a camera taking photos, it can only do this by absorbing photons that are a result of the ziyenza process. There are photons on the boundary, $b$, these are the photons the camera will take a picture of. such that

$$
Z_{a}=\mathrm{b} \text { per } t_{p}
$$

\section{Pulse of Light}

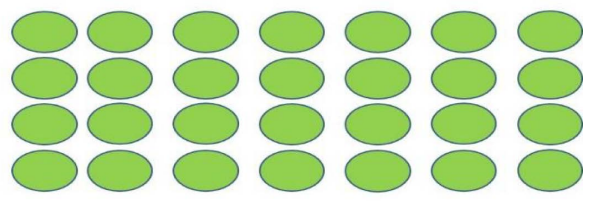

Figure 5. A pulse of light.

Pulse of Light

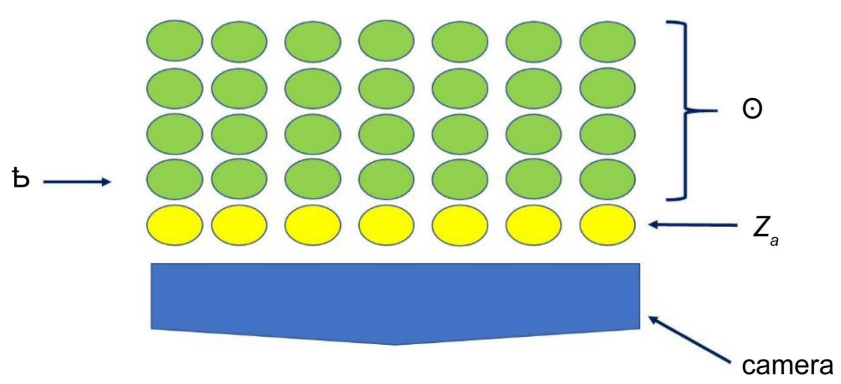

Figure 6. Ziyenza and a pulse of light. 
In Figure 6, ziyenza $=7$ photons per Planck time this means after 4 cycles the camera would have absorbed as much photons as the entire pulse of light, after 5 cycles, it has absorbed more photons than the pulse. That is the reality of the implications of known information.

The efficiency of the ziyenza process, $Z_{a y}$, can be expressed as the following relationship, ratio:

$$
Z_{a y}=\frac{\mathrm{b}}{\odot}
$$

The smaller the whole, $\odot$, in relation to the boundary, $b$, the more efficient is the ziyenza process.

At this point we can speculate about the amount of energy produced by the ziyenza process. The amount of energy produced

$$
\mathrm{e}=\mathrm{h} \#_{\mathrm{p}}
$$

where e is energy, $h$ is planck constant and $\#_{P}$ is the number of photons. If the Planck constant is correct as has been verified numerous times, this should be what is expected. In the above example of Figure 6, the amount of energy produced would be $7 \mathrm{~h}$ per $t_{p}$ more simply energy is equal to the Planck constant multiply the number of photons per Planck time.

\section{Conclusions}

Photons do not interact, it is impossible for the pulse of photon to be reflecting other photons. If seeing is believing, then it would be encouraged for one to watch this video "look what world most powerful laser is able to do" [3], from 0.46 minutes to 0.50 minutes you can clearly see for oneself lasers passing each other without interacting. Again, to appreciate this paper one must see the video for themselves, and it can be found here, https://www.youtube.com/watch?v=7baI2Nyi5rI. Again, true, lasers are not normal circumstances for a photon, but in the just mentioned video how do we see the laser when photons do not interact?

Experiments that have been done, taking a picture of photons proofs the concept of ziyenza is real and the hypothesis must be accepted.

Instead of cameras one could place other light sensors such as solar panels and we have a photon battery, well maintained lasting literally forever.

The reality is that a camera took a photo of photons, that can never be disputed, it means theoretically that all photons in the universe could have originated from one or a very few photons.

\section{References}

[1] Dillow, C. (2011) A Trillion-Frame-per Second Camera Captures Individual Photons Moving through Space Popular Science Magazine.

http://www.popsci.com/science/article/2011-12/trillion-frame-second-camera-captu res-photons-moving-through-space-slow-mo

[2] MMorpgCoreYT (2011) MIT-Photon Camera-Spreading Light in a Bottle. 
https://www.youtube.com/watch?v=_QAPQO6EL80

[3] Experiment at Home (2017) LOOK WHAT WORLD MOST POWERFUL LASER IS ABLE TO DO!!! https://www.youtube.com/watch?v=7baI2Nyi5rI

\section{Scientific Research Publishing}

Submit or recommend next manuscript to SCIRP and we will provide best service for you:

Accepting pre-submission inquiries through Email, Facebook, LinkedIn, Twitter, etc. A wide selection of journals (inclusive of 9 subjects, more than 200 journals)

Providing 24-hour high-quality service

User-friendly online submission system

Fair and swift peer-review system

Efficient typesetting and proofreading procedure

Display of the result of downloads and visits, as well as the number of cited articles

Maximum dissemination of your research work

Submit your manuscript at: http://papersubmission.scirp.org/

Or contactopj@scirp.org 